\title{
Article
}

\section{The effect of mountain bike wheel size on Cross-Country performance}

\author{
Hurst, Howard Thomas, Atkins, Stephen, Metcalfe, John, Sinclair, \\ Jonathan Kenneth and Rylands, Lee \\ Available at http://clok.uclan.ac.uk/15407/ \\ Hurst, Howard Thomas ORCID: 0000-0001-7889-8592, Atkins, Stephen, \\ Metcalfe, John ORCID: 0000-0002-8414-978X, Sinclair, Jonathan Kenneth \\ ORCID: 0000-0002-2231-3732 and Rylands, Lee (2016) The effect of mountain \\ bike wheel size on Cross-Country performance. Journal of Sports Sciences . \\ ISSN 0264-0414
}

It is advisable to refer to the publisher's version if you intend to cite from the work. http://dx.doi.org/10.1080/02640414.2016.1215498

For more information about UCLan's research in this area go to http://www.uclan.ac.uk/researchgroups/ and search for < name of research Group $>$.

For information about Research generally at UCLan please go to http://www.uclan.ac.uk/research/

All outputs in CLoK are protected by Intellectual Property Rights law, including Copyright law. Copyright, IPR and Moral Rights for the works on this site are retained by the individual authors and/or other copyright owners. Terms and conditions for use of this material are defined in the policies page.

\section{CLoK}

Central Lancashire online Knowledge www.clok.uclan.ac.uk

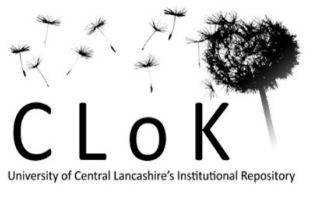




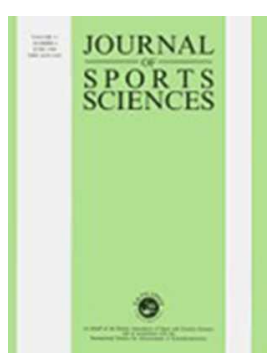

\section{The effect of mountain bike wheel size on Cross-Country performance}

\begin{tabular}{|r|l|}
\hline Journal: & Journal of Sports Sciences \\
\hline Manuscript ID & RJSP-2014-1198.R2 \\
\hline Manuscript Type: & Special Issue \\
\hline Keywords: & Power output, velocity, cadence, mountain biking \\
\hline \multicolumn{3}{c}{} \\
\\
\multicolumn{3}{c}{ SCHOLARONE } \\
\\
$\quad$
\end{tabular}

URL: http://mc.manuscriptcentral.com/rjsp 
1

2

3

4

5

6

7

8

9

10

11

12

13

14

15

16

17

18

19

20

21

22

23

24

25

26

27

28

29

30

31

32

33

34

35

36

37

38

39

40

41

42

43

44

45

46

47

48

49

50

51

52

53

54

55

56

57

58

59

60
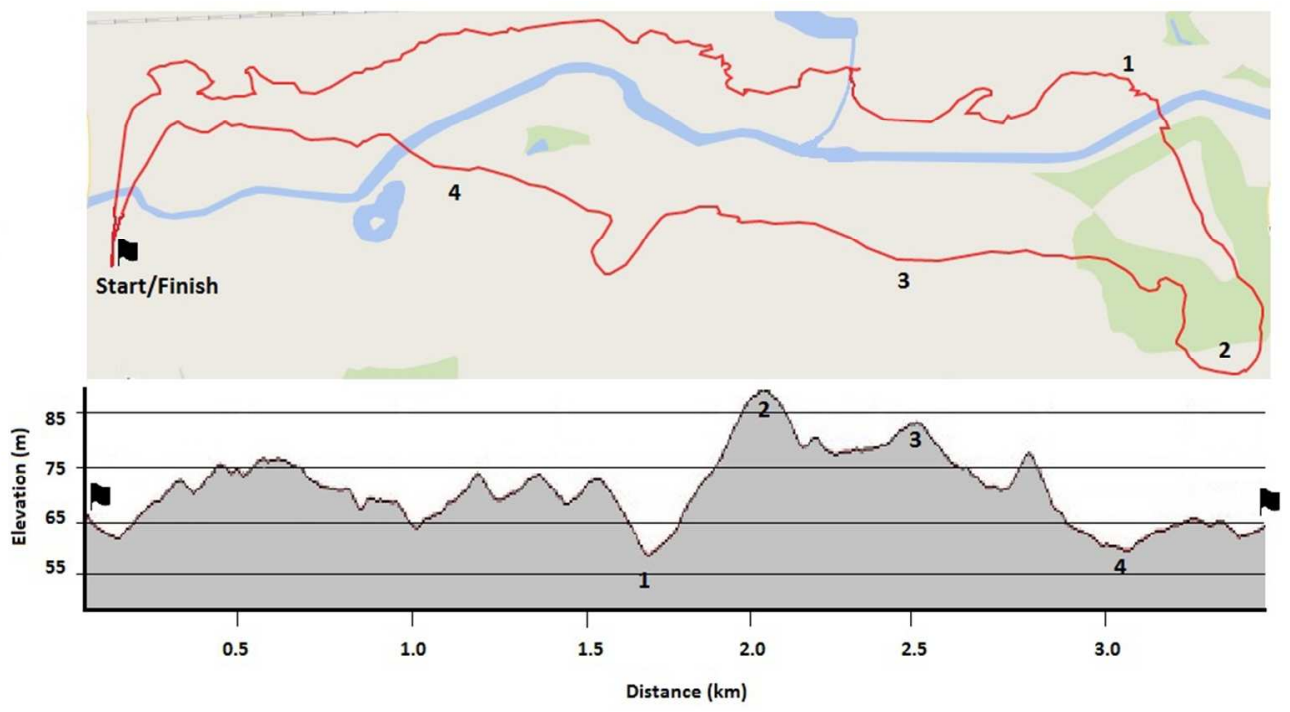

Course Profile

264x144mm (96 x 96 DPI)

URL: http://mc.manuscriptcentral.com/rjsp 
Wheel Size Overall Ascent Descent (inches)

\begin{tabular}{|c|c|c|c|c|}
\hline Time (s) & 26 & $916.11 \pm 54.45$ & $100.89 \pm 10.97$ & $173.11 \pm 9.79$ \\
\hline & 27.5 & $923.78 \pm 52.94$ & $107.33 \pm 8.40$ & $177.44 \pm 15.25$ \\
\hline & 29 & $904.22 \pm 54.77$ & $98.67 \pm 16.42$ & $176.67 \pm 19.72$ \\
\hline \multirow[t]{3}{*}{ Velocity $\left(\mathrm{km} \cdot \mathrm{h}^{-1}\right)$} & 26 & $13.72 \pm .77$ & $13.70 \pm 1.42$ & $13.77 \pm .80$ \\
\hline & 27.5 & $13.61 \pm .76$ & $12.81 \pm .95$ & $13.48 \pm 1.13$ \\
\hline & 29 & $13.91 \pm .84$ & $14.20 \pm 2.32$ & $13.62 \pm 1.70$ \\
\hline \multirow[t]{3}{*}{ Absolute Power } & 26 & $211.06 \pm 28.16$ & $250.47 \pm 52.90$ & $205.23 \pm 48.08$ \\
\hline & 27.5 & $211.50 \pm 31.71$ & $243.85 \pm 60.75$ & $179.57 \pm 28.42$ \\
\hline & 29 & $220.93 \pm 30.43$ & $237.91 \pm 27.61$ & $195.81 \pm 31.57$ \\
\hline \multirow{3}{*}{$\begin{array}{c}\text { Cadence } \\
\left(\operatorname{revs} \cdot \mathrm{min}^{-1}\right)\end{array}$} & 26 & $65 \pm 6$ & $74 \pm 5$ & $55 \pm 8^{*}$ \\
\hline & 27.5 & $67 \pm 7$ & $72 \pm 8$ & $59 \pm 9$ \\
\hline & 29 & $68 \pm 6$ & $71 \pm 5$ & $65 \pm 7$ \\
\hline \multirow[t]{3}{*}{ Work done $(\mathbf{K j})$} & 26 & $193.00 \pm 25.03$ & $25.33 \pm 6.43$ & $35.38 \pm 7.82$ \\
\hline & 27.5 & $195.20 \pm 29.31$ & $26.02 \pm 5.84$ & $31.75 \pm 4.67$ \\
\hline & 29 & $199.70 \pm 29.14$ & $23.64 \pm 5.54$ & $34.48 \pm 6.49$ \\
\hline
\end{tabular}

* Significantly different to 29 " wheel $(\mathrm{p}<.05)$.

URL: http://mc.manuscriptcentral.com/rjsp 


\section{Wheel Size (inches)}

\begin{tabular}{cccc} 
Correlation Between & $\mathbf{2 6}$ & $\mathbf{2 7 . 5}$ & $\mathbf{2 9}$ \\
\hline Stature and Absolute Power (W) & $r=.56, \mathrm{p}=.12$ & $r=.63, \mathrm{p}=.06$ & $r=.71, \mathrm{p}=.08$ \\
Stature and Velocity $\left(\mathrm{km} . \mathrm{h}^{-1}\right)$ & $r=.43, \mathrm{p}=.25$ & $r=.14, \mathrm{p}=.73$ & $r=.13, \mathrm{p}=.73$ \\
Stature and Cadence (revs.min $\left.{ }^{-1}\right)$ & $r=.45, \mathrm{p}=.22$ & $r=.29, \mathrm{p}=.45$ & $r=.40, \mathrm{p}=.29$ \\
Stature and Relative Power $\left(\mathrm{W} . \mathrm{Kg}^{-1}\right)$ & $r=.38, \mathrm{p}=.31$ & $r=.59, \mathrm{p}=.09$ & $r=.69, \mathrm{p}=.06$ \\
\hline
\end{tabular}


1 The effect of mountain bike wheel size on Cross-Country performance

2 Running head: Mountain bike wheel size and performance

3 Keywords: Power output, velocity, cadence, mountain biking,

\section{5}

\section{Acknowledgments}

7 We would like to thank Santa Cruz Bicycles in the USA and UK for their support in this 8 study. We could also like to confirm there were no conflicts of interest and that Santa Cruz

9 Bicycles' involvement was completely impartial. We would also like to thank the participants 10 for their time and effort in taking part in the study. 
2 The purpose of this study was to determine the influence of different wheel size diameters on 3 indicators of cross-country mountain bike time trial performance. Nine competitive male 4 mountain bikers (age $34.7 \pm 10.7$ yrs; stature $177.7 \pm 5.6 \mathrm{~cm}$; body mass $73.2 \pm 8.6 \mathrm{~kg}$ ) 5 performed one lap of a $3.48 \mathrm{~km}$ mountain bike course as fast as possible on 26", 27.5" and 629 " wheeled mountain bikes. Time (s), mean power (W), cadence $\left(\right.$ revs $\left.\cdot \mathrm{min}^{-1}\right)$ and velocity $7 \quad\left(\mathrm{~km} \cdot \mathrm{h}^{-1}\right)$ were recorded for the whole lap and during ascent and descent sections. One-way 8 repeated measure ANOVA were used to determine significant differences. Results revealed 9 no significant main effects for any variables by wheel size during all trials, with the exception 10 of cadence during the descent $\left(\mathrm{F}_{(2,16)}=8.96 ; \mathrm{p}=.002 ; \mathrm{p}^{2}=.53\right)$. Post hoc comparisons 11 revealed differences lay between the 26 " and 29 " wheels $(\mathrm{p}=.02)$. The findings indicate that 12 wheel size does not significantly influence performance during cross-country when ridden by 13 trained mountain bikers, and that wheel choice is likely due to personal choice or sponsorship 14 commitments. 
2 Cross-country Mountain biking has been a recognised Olympic discipline since the 1996 duration being performed at or above the lactate threshold. In addition, mean power output 11 during cross-country racing has been reported to be approximately $240-250 \mathrm{~W}$ or $\sim 3.5 \mathrm{~W}^{\mathrm{kg}} \mathrm{kg}^{-1}$ 12 in elite male racers (Stapelfeldt et al., 2004; Macdermid \& Stannard, 2012). Macdermid et al. 13 (2012) also reported a mean cadence of $76 \mathrm{revs} \cdot \mathrm{min}^{-1}$ during cross-country riding at selfselected race pace.

Several studies have also investigated the influence of mountain bike design, specifically the use of suspension systems, on performance (Seifert, Luetkemeier, Spencer, Miler, \& Burke, 1997; MacRae, Hise, \& Allen, 2000; Nishii, Umemura, \& Kitagawa, 2004; Levy \& Smith, 2005). These studies have shown that power output is generally higher when suspension is used than without, most likely the result of energy losses through the systems requiring greater effort to maintain propulsion. However, few studies have investigated to influence of different wheel diameters on mountain biking performance. 
1 Since the inception of mountain biking the standard wheel diameter has been 26 ". However, 2 more recently manufacturers have developed and promoted 27.5 " and 29 " wheel diameter

3 mountain bikes. Much subjective debate has occurred regarding the potential advantages and 4 disadvantages of each of the three options. The vast majority of the debate has revolved 5 around anecdotal evidence of improved speed and performance with the larger wheel size, 6 with scant information being derived from empirical studies. Macdermid, Fink, and Stannard 7 (2014) reported that at the 2012 Olympic Games the split between 26”, 27.5" and 29" wheel

8 bikes was 5, 25 and $70 \%$ respectively, with the men's gold and bronze medals being won on 9 a 29" wheel bike, with silver being won on a 27.5 " wheel. In the women's race gold, silver and bronze medals were won on 26", 27.5" and 29" wheeled bikes respectively. Macdermid et al. (2014) investigate the performance characteristics when riding a 26 " and 29 " wheeled mountain bike. They found that no significant differences existed between the two wheel sizes in mean power output over a single lap at race pace, or during ascent and descent sections. Despite this, they did report significant differences in lap duration, with the 29" wheel diameter bike being significantly quicker than the 26 " version (mean lap times $635 \mathrm{~s}$ and $616 \mathrm{~s}$, respectively). However, their study didn't report cadence data or values for the increasingly popular 27.5" wheel standard. Many mountain bike manufacturers are gradually phasing out of 26 " diameter wheels in favour of the 27.5 " diameter. However, there remains no scientific evidence to support this trend, or the proposed benefits of the 27.5 " diameter wheel for MTB performance, other than anecdotal. 


\section{Materials and methods}

3 Participants

4 Ethical approval for this study was granted by the University of Central Lancashire Ethics

5 Committee and in accordance with the Declaration of Helsinki. Nine male competitive

6 mountain bikers (age $34.7 \pm 10.7 \mathrm{yrs}$; stature $177.7 \pm 5.6 \mathrm{~cm}$; body mass $73.2 \pm 8.6 \mathrm{~kg}$ ) took

7 part in the study. All riders were sub-elite, though competed at National level in their

8 respective age categories, and had at least 5 years racing experience. Participants were

9 informed both verbally and in writing of the test procedures, and written informed consent

10 was obtained. Prior to testing, it was determined that all participants had previous experience 11 of riding both 26 " and 29" wheel diameter bicycles, but none reported riding a 27.5" variant.

\section{Course Profile}

Testing took place on three days over a four week period between June and July on a purpose build cross-country mountain bike course at the British National Cycle Centre (Clayton Vale, Manchester). Mean ambient temperature over the testing sessions was $18.5 \pm 1.5{ }^{\circ} \mathrm{C}, 50.9 \pm$ $3.7 \%$ humidity and sunny. Track conditions were dry for all test sessions. As a result, course conditions were comparable for all riders. The course was typically representative of the terrain riders would encounter during a UK cross-country race, and is itself used for regional 20 races. The course profile presented in figure 1 was recorded using a Garmin Edge 810 GPS cycle computer. However, due to tree cover on the course and the impact this has on GPS accuracy, GPS data was not used during analysis for the determination of distance and 
1 velocity. Instead, accurate distances were recorded in metres using a calibrated trundle wheel 2 and subsequently mean velocity $\left(\mathrm{km} \cdot \mathrm{h}^{-1}\right)$ was manually calculated.

4 Therefore, the GPS system was used purely to provide a representative schematic of the 5 course (figure 1). Distances of each section highlighted in figure 1 were; Start to $1=1.72 \mathrm{~km}$; 61 to $2=0.38 \mathrm{~km}(\mathrm{Climb}) ; 2$ to $3=0.47 \mathrm{~km} ; 3$ to $4=0.66 \mathrm{~km}$ (Descent); and 4 to Finish $=$ $7 \quad 0.25 \mathrm{~km}$; total lap distance $=3.48 \mathrm{~km}$. Based on the mean GPS data from all laps, the average 8 gradient of the climb was $5.8 \pm 0.3 \%$, whilst the descent gradient was $-6.1 \pm 0.4 \%$. Though 9 the accuracy of this may be debated, it was not possible to gain the gradient information via 10 another method.

\section{Equipment}

15 All bicycles were full suspension cross-country mountain bikes with $100 \mathrm{~mm}$ of rear suspension travel and $120 \mathrm{~mm}$ front suspension (Superlight, Santa Cruz Bicycles, USA). The

17 bicycles were 2014 models and were new and unused prior to testing. Each bicycle was the same model and fitted with identical components with the exception of wheel size. All frames 19 geometries were designed to optimise the bicycles for their respective wheel sizes by the manufacturer. All three bicycles had a size medium frame. Top tube lengths were 590, 602 21 and $613 \mathrm{~mm}$ for the 26 ", 27.5 " and 29 " wheels respectively, whilst bottom bracket heights 22 were 319,326 and $337 \mathrm{~mm}$, respectively. To accommodate differences in rider stature a 
choice of two different stem lengths were offered (90 and $110 \mathrm{~mm})$. Saddle setback was also

2 adjusted to ensure best fit. In addition, riders were allowed to use their own pedals.

4 Bicycle mass differed due to the differences in wheel diameter and wheel mass (13.69 kg, $5 \quad 13.93 \mathrm{~kg}$ and $14.15 \mathrm{~kg}$ for the 26", 27.5" and 29" wheeled bicycles respectively). Mass of the 6 bicycles is inclusive of powermeter and GPS head unit. Therefore, as the focus of the study

7 was on the influence of wheel size on performance and not differences in bicycle/wheel mass,

8 the mass was standardised to the heaviest bicycle (29" wheeled) by adding small weights to 9 the lower downtube of the 26" and 27.5" wheeled bicycles. Suspension shocks were set up 10 according to the manufacturers' recommendations for each rider's individual body mass to 11 allow 10 percent sag in the travel, whilst shock leverage ratios were optimised by Santa Cruz 12 for each frame geometry. Tyre pressure was run at 35 psi for all trials to ensure consistency. 
1 Whilst the Garmin Edge 810 was not used to record distance or velocity, it was paired via 2 ANT+ wireless protocol to the SRM and used to record time (s), mean power output (W) and 3 mean cadence (revs $\cdot \mathrm{min}^{-1}$ ) throughout each lap and during selected ascent and descent 4 sections. Data were sampled at $1 \mathrm{~s}$ intervals. As GPS data were not used, riders were 5 instructed to press the 'lap' button on the handlebar mounted GPS computer when they 6 passed the start and end points of the designated ascent and descent sections of the course. 7 These sections were clearly signposted on the course with coloured tape attached to trees.

8 This allowed us to analyse data for these sections in isolation, along with the whole lap based 9 on the distances measured with the trundle wheel and the lap times recorded.

\section{Protocols}

Participants were required to ride one lap of the course on each of the three test bicycles in a randomised order, with each lap being performed as fast as possible. Riders performed each

of their three laps on the same day, with thirty minutes passive rest between laps to allow sufficient recovery time. Each lap was then preceded by a 10 min re-warm, consisting of low intensity cycling. All riders had previous experience of riding the course with the exception of one participant. All riders were allowed 1 hour to familiarise themselves with the course and the bicycles.

\section{Statistical Analyses}

Data were first downloaded from the GPS head unit to the Garmin Connect online database. Data were subsequently exported to Microsoft Excel before being analysed using the SPSS statistical software (SPSS Inc., version 20.0, Chicago, Illinois, USA). Data were confirmed to 
1 be normally distributed by means of a Shapiro-Wilk test. Differences in overall, ascent and 2 descent time (s), mean velocity, power, cadence and work done were analysed using one-way

4 Bonferroni corrections were employed during post hoc analyses. Effect sizes were calculated 5 using a partial $\operatorname{Eta}^{2}\left(\eta^{2}\right)$. The influence of stature on performance indicators was determine 6 using Pearson Product Moment Correlations. Significance was accepted at the $\mathrm{p} \leq 0.05$ level 7 (Sinclair et al. 2013) and descriptive data were presented as mean \pm standard deviation.

8

\section{Results}

$* * *$ Table 1 near here***

When performance parameters were analysed over the duration of the full lap, no significant main effects for wheel size were found for time $\left(\mathrm{F}_{(2,16)}=.70 ; \mathrm{p}=.51 ; \eta^{2}=.08\right) ;$ velocity $\left(\mathrm{F}_{(2}\right.$, $\left.\left.{ }_{16}\right)=.70 ; p=.45 ; \eta^{2}=.08\right) ;$ absolute power $\left(\mathrm{F}_{(2,16)}=2.98 ; \mathrm{p}=.96 ; \eta^{2}=.27\right)$; work done $\left(\mathrm{F}_{(2}\right.$ $\left.{ }_{16)}=.68 ; \mathrm{p}=.52 ; \eta^{2}=.08\right)$ or cadence $\left(\mathrm{F}_{(2,16)}=3.53 ; \mathrm{p}=.06 ; \eta^{2}=.31\right)$. When data were analysed for the selected ascent, no significant main effects were again found for time $\left(\mathrm{F}_{(2,16)}\right.$ $\left.=1.05 ; \mathrm{p}=.37 ; \eta^{2}=.12\right) ;$ velocity $\left(\mathrm{F}_{(2,16)}=1.42 ; \mathrm{p}=.27 ; \eta^{2}=.15\right) ;$ absolute power $\left(\mathrm{F}_{(2,16)}=\right.$ $\left..19 ; \mathrm{p}=.83 ; \eta^{2}=.02\right)$; work done $\left(\mathrm{F}_{(2,16)}=.48 ; \mathrm{p}=.66 ; \eta^{2}=.05\right)$ or cadence $\left(\mathrm{F}_{(2,16)}=.84 ; \mathrm{p}=\right.$ $\left..45 ; \eta^{2}=.10\right)$. Similarly, no significant main effects were found during the descent section; time $\left(\mathrm{F}_{(2,16)}=.20 ; \mathrm{p}=.72 ; \eta^{2}=.02\right) ;$ velocity $\left(\mathrm{F}_{(2,16)}=.48 ; \mathrm{p}=.55 ; \eta^{2}=.06\right) ;$ work done $\left(\mathrm{F}_{(2}\right.$ $\left.{ }_{16)}=.79 ; \mathrm{p}=.47 ; \eta^{2}=.09\right)$ or absolute power $\left(\mathrm{F}_{(2,16)}=1.17 ; \mathrm{p}=.34 ; \eta^{2}=.13\right)$. However, $\mathrm{a}$ significant main effect was found for cadence during the descent $\left(F_{(2,16)}=8.96 ; p=.002 ; \eta^{2}=\right.$ .53). Post hoc comparisons revealed that cadence was significantly lower $(\mathrm{p}=.02)$ when 
1 riding with the 26 " when compared to the 29 " wheel. Table 1 presents the mean \pm standard 2 deviation values for all performance parameters during each phase of testing.

4 The same size frames with a selection of stem lengths were used to accommodate the 5 differences in participant stature. Therefore, data were analysed to determine whether these 6 differences in stature had any influence of performance variables between wheel sizes,

7 despite the same size frame for each bicycle. No significant relationships were found between 8 stature and any of the performance variables recorded. Table 2 presents the Pearson Product 9 Moment correlation results.

$* * *$ Table 2 near here***

\section{Discussion}

14 This study aimed to determine the effect of different mountain bike wheel diameters on 15 performance indicators, during an off-road time trial. To the authors' knowledge, this represents the first study to investigate the influence of all three current MTB wheel size standards, 26", 27.5" and 29". The key findings were that no significant differences were observed in relation to time, power, velocity, cadence or work done when analysed for the 19 full lap, ascent and descent. The only exception to this was the significant difference in 20 cadence between the 26 " and 29 " during the selected descent phase. Subsequently, the 21 hypothesis that the 29" wheel would statistically improve performance over the smaller 22 wheels has to be rejected. 
2 Mean power output for the full lap was lower than that reported previously for XCO-MTB 3 racing (Stapelfeldt et al., 2004; Impellezzeri et al., 2007; Macdermid et al., 2014), 4 irrespective of wheel size. This is likely to be due to the sub-elite level of the riders in the 5 present study compared to elite riders in the aforementioned studies. In addition, the lower 6 mean power output may also have been influenced by the relatively technical and twisty 7 nature of the course used in the present study, as this would determine when and how long riders could apply power for. Previous research by Hurst and Atkins (2006) alluded to how 9 differences in terrain affected power production. Cadence was also lower than that reported in previous studies (Macdermid et al., 2012). This again may be attributable to difference in course terrain and the opportunity to pedal. Though not significantly different, power output and cadence were greater for the 29" wheel when compared to the smaller diameter wheels. Effect sizes revealed approximately $27 \%$ and $31 \%$ of the variance in mean power and cadence over the full lap was attributable to the experimental conditions. Though around two thirds of the variance was likely due to random errors, the remaining variance may have been influenced by greater contact time between the ground and tyres, and the ability of the larger

wheel diameter to roll over small bumps in the trail more effectively. This would potentially enable the rider to produce power and maintain cadence more consistently throughout the lap, leading to the slightly higher values observed. Indeed, increased ground contact and 'rollover' ability is one of the key benefits of 29" wheels promoted by manufacturers, whilst reduced vibrations have also been reported with larger wheels (Wilson, 2004). However, contrary to this Macdermid et al (2014), found hardtail 29" wheels actually increased vibrations over 26" a wheeled hardtail. However, some of the differences between studies could again be influenced by differences in course terrain. 
1 Differences in overall lap times did not reach a level of significant difference, whilst effect 2 size revealed only approximately $8 \%$ of the variances in lap times could be attributed to the 4 wheel was on average $1.3 \%$ quicker than the 26 " and $2.1 \%$ quicker than the 27.5 " wheels 5 over the duration of the full lap. Interestingly, Macdermid et al. (2014) reported similar, 6 though significant, gains in time between 29" and 26" wheels during an cross-country 7 mountain bike time trials. Though only $\sim 1-2 \%$ quicker and non-significant, like Macdermid 8 et al. (2014), results were collected from a single lap time trail. Despite this the results from 9 the 29" wheel are interesting nonetheless, and over a full race distance with multiple laps, indicate 29" wheels may potentially offer a greater advantage over smaller wheel sizes. 11 Further research under full race conditions is warranted.

Based on the proposed improved rolling properties of larger wheels, the 27.5" wheel should in theory have also been quicker than the 26 " diameter wheel bicycle. However, in order to optimise the bicycles' performance for each wheel size, geometry did differ between frames, which may have contributed to the results. The wheelbase length of the 27.5 " was longer by almost $10 \mathrm{~mm}$ than the other two wheel sizes, with the difference between the 26 " and 29 " being only $1.6 \mathrm{~mm}$. As a result, the longer wheelbase may have negatively affected handling of the 27.5 " wheel on the relatively technical course used in the present study, leading to the slowest overall lap times observed. Macdermid et al. (2014) reported using a 26" wheel in a frame designed for a 29" diameter wheel, though claimed the observed difference of $10 \mathrm{~mm}$ in mechanical trail, a key determinant of a bicycles' handling properties, would not affect the bicycles performance. However, the findings of the present study would seem to refute this. 
1 Differences during the ascent and descent sections were again non-significant between wheel 2 sizes for all variables except descent cadence, with effects sizes revealing a relatively small 3 amount of variance (range 2-15\%) for each parameter could be attributable to the 4 experimental conditions. During the climb the 29 " was only marginally quicker than the 26 ", 5 though was around 10 seconds faster than the 27.5 " over the $380 \mathrm{~m}$ long climb. However, 6 velocity was $3.5 \%$ and $9.8 \%$ higher for the 29 " than the 26 " and 27.5 ", respectively, for 7 power output that was $5.1 \%$ and $2.4 \%$ lower than the 26 " and 27.5 " wheels respectively. 8 Again, though not to a level of significance, this may, to a small extent, be influenced by the 9 proposed better rolling qualities of the larger 29" wheel, resulting in less effort being required to maintain forward propulsion and therefore velocity. This supposition, is in part supported 11 by the lower work done, as indicated by the lower kilojoules observed during the ascent section for the 29 " wheel over the other two sizes. Though this too did not reach a level of significance, the 29 " required on average $6.7 \%$ less work to ascend than the 26 " wheel, and $9.2 \%$ less than the 27.5 " wheel. However, this does not explain why the 27.5 " wheel proved to be the slowest over the ascent. This wheel size is relatively new and has been promoted as a 'best of both' option between the better manoeuvrability of the 26 " and the better rolling properties of the 29" wheel, yet the results of the present study do not support this logic. Despite this, it would be unfair to label the 27.5 " as the worst performing bicycle tested. Reported differences were not significantly different to the other two wheel diameters, as such any differences may simply have been due either to random errors.

During the descent section the 26 " diameter wheel was approximately $2 \%$ quicker than the 27.5 " and 29" diameter wheels. Though these differences were again not significant, some of the variance could have been the result of improved stability and therefore control during the tighter more technical sections of the descent compare to the 29", resulting from the lower 
1 bottom bracket height ( $319.7 \mathrm{~mm}$ and $337.6 \mathrm{~mm}$, for 26" and 29", respectively). However, 2 this does not explain why the 27.5 " wheel was slower, as this too had a lower bottom bracket 3 height than the 29" wheel. The slower times of the 27.5 " wheel during the descent may again 4 have been due to the longer wheelbase compromising handling on the tight, twisty sections of 5 the descent. This may have led to participants slowing more into corners to get round them, 6 whilst the higher cadence seen during descending for the 27.5 " and 29 " trials may have been 7 the result of riders having pedal faster out of corners to get back up to speed.

8

\section{$9 \quad$ Limitations}

Possible limitations to the present study are the lack of physiological measures such as heart rate and oxygen uptake. However, given the rapid changes in effort associated with crosscountry mountain biking and the lag time in heart rate response to changes in intensity, it was anticipated that heart rate would change little in response to the different wheel sizes and therefore yield little benefit to the study. In addition, previous studies have shown heart rate to be remarkably consistent throughout mountain bike races, potentially due to increased isometric muscular activity over that observed in road cycling (Hurst \& Atkins, 2006), and as a result of possible increases in adrenaline levels and subsequent stimulation of the sympathetic nervous system (Sperlich, Achtzehn, Buhr, Zinner, Zelle, \& Holmberg, 2012). Oxygen uptake, was not monitored during the present study despite being used in previous research (MacRae et al., 2000; Macdermid et al., 2012). The authors of the present study felt that although this may have been of interest, the increased mass of the equipment and the intrusive nature of wearing a facemask may have influenced the natural riding dynamics of the participants, thus compromising the ecological efficacy of the investigation. Indeed, feedback from riders during pilot testing reported the gas analyser and facemask restricted 
movement and increased discomforted due to sweat build up in the facemask. Therefore, the

2 decision was made not to monitor this variable.

3

4 Though participants were given time to familiarise themselves with the course and the

5 bicycles, this may not have been sufficient to learn the full capabilities of the relatively newer

627.5 " wheel size. It is also accepted that multiple timed laps on different courses are need to

7 fully determine the extent of any differences between wheel sizes. However, the current

8 findings are still of interest nonetheless. Finally, though riders were not 'blinded' to the data

9 on the GPS unit, it is unlikely that this would have led to changes in pacing strategies, are 10 riders were more likely to be focusing on the trail ahead than looking at the handlebar 11 mounted unit, particularly given the relatively technical nature of the course used.

\section{Conclusions}

To summarise, the present study revealed no statistically significant differences for all recorded parameters between the three wheel sizes, with the exception of cadence during the downhill section. However, further research over a full race distance is warranted to determine if the small but non-significant differences observed over a one lap time trial in the present study lead to significant benefits or drawbacks over the course of a race. In addition, it is important to note that the findings of the present study only relate to the particular course used, and as alluded to by previous research, results may differ depending upon terrain. 
Gregory, J., D. Johns, and J. Walls. (2007) Relative vs absolute physiological measures as predictors of mountain bike cross-country race performance. Journal of Strength \& Conditioning Research, 21, 17-22.

Hurst, H.T., and S. Atkins. 2006. Power output of field-based downhill mountain biking. Journal of Sports Sciences, 24, 1047-1053.

Impellizzeri, F., and S. Marcora. (2007) The physiology of mountain biking. Sports Medicine, 37, 59-71.

Impellizzeri, F., E. Rampinini, A. Sassi, P. Mognoni, and S. Marcora. (2005) Physiological correlates to off-road cycling performance. Journal of Sports Sciences, 23, 41-47.

Jones, S.M. and Passfield, L. (1998) The dynamic calibration of bicycle power measuring cranks. In Haake, S.J. (ed). The Engineering of Sport, Oxford, Blackwell Science, 265-274.

Lawton, E.W., Martin, D.T. and Lee, H. (1999) Validation of SRM powercrank using dynamic calibration. $5^{\text {th }}$ IOC World Congress on Sport Sciences, Sydney, Australia, 31 Oct-5 Nov.

Levy, M. and Smith, G. (2005) Effectiveness of vibration damping with bicycle suspension systems. Sports Engineering, 8, 99-106.

Macdermid, P.W., Fink, P.W. and Stannard R. (2014) Transference of 3D accelerations during cross country mountain biking. Journal of Biomechanics, 47, 1829-1827.

Macdermid, P.M. and Stannard, S. (2012) Mechanical work and physiological responses to simulated cross country mountain bike racing. Journal of Sports Science, 30, 1491-1501.

MacRae, H.S.H., K.J. Hise, and P.J. Allen. (2000) Effects of front and dual suspension mountain bike systems on uphill cycling performance. Medicine and Science in Sports and Exercise, 32, 1276-1280.

Martin, J.C., Milliken, D.C., Cobb, J.E., McFadden, K.L. and Coggan, A.R. (1998) Validation of a mathematical model for road cycling power. Journal of Applied Biomechanics, 14, 276-291.

Nishii, T., Umemura, Y. and Kitagawa, K. (2004) Full suspension mountain bike improves off-road cycling performance. Journal of Sports Medicine and Physical Fitness, 44, 356-360.

Seifert, J.G., Luetkemeier, M.J., Spencer, M.K., Miller, D. and Burke, E.R. (1997) The effects of mountain bike suspension systems on energy expenditure, physical exertion, and time trial performance during mountain bicycling. International Journal of Sports Medicine, $18,197-200$.

42 Sinclair, J., Taylor, P.J. and Hobbs, S.J. (2013) Alpha level adjustments for multiple 43 dependent variable analyses and their applicability - A review. International Journal of Sport 44 Science and Engineering, 7, 17-20. 
Sperlich, B., S. Achtzehn, M. Buhr, C. Zinner, S. Zelle, and H-C. Holmberg. (2012) Salivary cortisol, heart rate, and blood lactate responses during elite downhill mountain bike racing. International Journal of Sports Physiology and Performance, 7, 47-52.

Stapelfeldt, B., A. Schwirtz, Y.O. Schumacher, and M. Hillebrecht. (2004) Workload demands in mountain bike racing. International Journal of Sports Medicine, 25, 294-300.

Warner, S., J. Shaw, and G. Dalsky. (2002) Bone mineral density of competitive male mountain and road cyclists. Bone, 30, 281-286.

Wilber, R.L., K.M. Zawadzki, J.T. Kearney, M.P. Shannon, and D. Disalvo. (1997) Physiological profile of elite off-road and road cyclists. Medicine and Science in Sports and Exercise, 29, 1090-1094.

Wilson. (2004) Bicycling Science. Mit Press. 
4

5

6

7

10

11

12

13

14

15

16

17

18

19

20

21

22

23

24

25

26

27

28

29

30

31

32

33

34

35

36

37

38

39

40

41

42

43

44

45

46

47

48

49

50

51

52

53

54

55

56

57

58

59

60

Journal of Sports Sciences

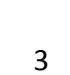

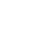

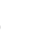$$
\begin{aligned}
& 21 \\
& 23 \\
& 25 \\
& 26 \\
& 27 \\
& 28 \\
& 30 \\
& 31 \\
& 32 \\
& 33 \\
& 34 \\
& 35 \\
& 36 \\
& 37 \\
& 38 \\
& 39 \\
& 40 \\
& 41 \\
& 42 \\
& 43 \\
& 44 \\
& 45 \\
& 46 \\
& 47 \\
& 48 \\
& 49 \\
& 50 \\
& 51 \\
& 52 \\
& 53 \\
& 54 \\
& 55 \\
& 56 \\
& 57 \\
& 58 \\
& 59 \\
& 60
\end{aligned}
$$

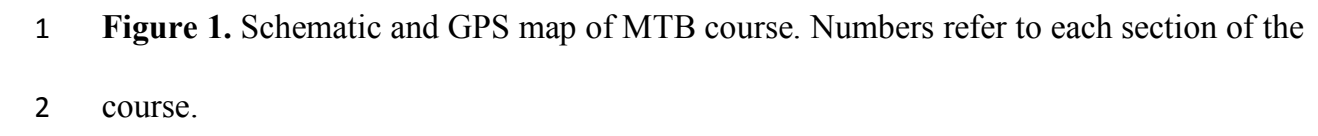

.

(1)

(1)

(1)


6

7

8

9

10

11

12

13

14

15

16

17

18

19

20

21

22

23

24

25

26

27

28

29

30

31

32

33

34

35

36

37

38

39

40

41

42

43

44

45

46

47

48

49

50

51

52

53

54

55

56

57

58

59

60

1 Table 1. Mean \pm standard deviation for mean performance variables recorded during the full

2 lap and during the selected ascent and descent phases.

3 
1 Table 2. Pearson Product Moment Correlation coefficient $(r)$ between stature and 2 performance variables for each wheel diameter $(N=9)$. 